\title{
EFECTOS DE INTERACCIÓN SUELO-ESTRUCTURA EN EDIFICIOS CON PLANTA BAJA BLANDA
}

\author{
Luciano R Fernández Sola ${ }^{(1)}$ y Javier Avilés López ${ }^{(2)}$
}

\begin{abstract}
RESUMEN
Las estructuras con planta baja flexible son muy vulnerables a la acción de sismos. Esto es debido, principalmente, a la falta de rigidez y resistencia en el piso blando. Las Normas Técnicas Complementarias para Diseño por Sismo del RCDF tratan el problema como una condición de irregularidad estructural, limitándose a reducir el factor de comportamiento sísmico que controla las resistencias de diseño. De esta forma se aumenta la capacidad de rigidez y resistencia de toda la estructura, pero no se corrige el contraste que existe entre el piso blando y el resto de los entrepisos. En este trabajo se desarrolló un modelo numérico para estimar la respuesta dinámica de estructuras con planta baja flexible desplantadas sobre suelo blando. El modelo es elástico y tiene en cuenta el alargamiento del periodo estructural debido a la flexibilidad del suelo, así como el incremento en el amortiguamiento debido a la disipación de energía por radiación de ondas en el suelo. Considerando que el amortiguamiento está distribuido a lo largo del edificio, se construye una matriz de amortiguamiento clásico para la estructura sola usando amortiguamiento modal. Para el suelo, en cambio, se considera amortiguamiento elemental haciendo uso de amortiguadores viscosos para los distintos modos de vibrar de la cimentación. Debido a que el sistema acoplado suelo-estructura carece de modos clásicos de vibrar, la respuesta estructural se obtiene con el método de la respuesta compleja en la frecuencia.
\end{abstract}

\begin{abstract}
First soft-story structures are very vulnerable under the action of seismic forces. This is due principally to the lack of stiffness and strength in the soft story. The Complementary Technical Norms for Seismic Design of the RCDF handles this problem as a structural irregularity, just by reducing the seismic behavior factor controlling the design strengths. By doing this, the stiffness and strength capacity of the entire structure is increased, but the existing contrast between the soft story and the rest of the structure is not corrected. This work has developed a numerical model to estimate the dynamic response of first soft-story structures on soft soil. The model is elastic and takes into account the structural period increase due to the soil flexibility, as well as the damping increase due to the energy dissipation by wave radiation into the soil. Considering that the structural damping is distributed along the building, a classical damping matrix for the structure alone is assembled using modal damping. On the contrary, for the supporting soil, elemental damping is considered making use of viscous dashpots for each of the foundation vibration modes. Due to the
\end{abstract}

Artículo recibido el 7 de julio de 2007 y aprobado para su publicación el 1 de octubre de 2008. Se aceptarán comentarios y/o discusiones hasta cinco meses después de su publicación

(1) Instituto de Ingeniería, UNAM, Ciudad Universitaria, 04510, México D.F., lfernandezs@iingen.unam.mx

(2) Instituto Mexicano de Tecnología del Agua, Jiutepec, Morelos, javiles@tlaloc.imta.mx 
lack of classic modes of vibration for the coupled soil-structure system, the structural response has to be obtained by the complex frequency-response method.

\section{INTRODUCCIÓN}

En el diseño y desempeño sísmico de estructuras, los parámetros como el periodo natural de vibrar, las formas modales y el amortiguamiento asociado a la estructura son determinantes. El comportamiento ante grandes deformaciones y no linealidades en los materiales también definen de manera importante el nivel de seguridad estructural.

Una condición fundamental para asegurar el correcto trabajo de las edificaciones, es mantener cierta regularidad del sistema estructural tanto en planta como en elevación. Problemas tales como el colapso total debido a la falla de uno de los entrepisos, concentración de esfuerzos en elementos perimetrales, deficiente desempeño de columnas debido a la presencia de efectos de segundo orden (P- $\Delta$ ), entre otros, son producto de la irregularidad estructural.

Entre los problemas estructurales más comunes y peligrosos encontramos el llamado primer piso blando. Este problema se presenta cuando el primer entrepiso de un edificio cuenta con una rigidez considerablemente menor en relación con el siguiente nivel.

Considerar la influencia del piso blando en la disminución de la capacidad de deformación de la estructura es razonable, como lo hace el Reglamento de Construcciones del Distrito Federal, porque al concentrar todas las deformaciones del edificio en un solo nivel es necesaria una ductilidad local mucho mayor en los elementos de este entrepiso para conseguir una misma ductilidad a nivel global. Pero al tomar un factor de comportamiento sísmico menor, y bajo el enfoque de diseño del reglamento, solamente se diseña para fuerzas más grandes, lo que produce elementos estructurales de mayores dimensiones, pero mantiene el contraste de rigideces entre los niveles. El problema en este caso es que la amplificación dinámica de la respuesta, y por tanto la distorsión de entrepiso a la que estará sujeto el piso blando, no se disminuye al aumentar la rigidez cuando se considera únicamente el comportamiento elástico.

En el diseño sísmico de estructuras con planta baja flexible desplantadas sobre suelo blando, la interacción dinámica duelo-estructura (ISE) adquiere relevancia significativa debido a la presencia de efectos P-delta. En edificios con primer piso blando estos efectos son muy dañinos, producto de la concentración de la deformación de toda la estructura en el primer nivel donde las cargas verticales sobre las columnas son muy altas. Los efectos de ISE, al introducir cabeceo, hacen más drásticos los efectos Pdelta.

Desde el punto de vista de la dinámica del sistema, tanto el primer piso blando como los efectos de ISE se reflejan en un cambió de la rigidez, lo que lleva a pensar que ambos fenómenos podrían tener características similares. Si se hace una analogía entre ambos efectos (ISE y entrepiso blando), se antoja lógico considerar la presencia de un primer piso blando como un estrato de suelo en el cuál está desplantada una estructura equivalente a los niveles superiores, en otras palabras, un caso de base flexible igual al de los efectos de ISE. De esta manera, se puede ver que la diferencia principal desde el punto de vista estructural entre ambos efectos es la menor capacidad de deformación que tiene el piso blando antes de colapsar, en comparación a las deformaciones que puede sufrir el suelo sin fallar.

En este trabajo se analizó la variación de las funciones de transferencia y las respuestas de estructuras con primer piso blando, debido a la presencia de base flexible. El modelo que se utiliza es el de 
viga de cortante. Las rigideces de entrepiso se representan por medio de resortes individuales que conectan a masas consecutivas. El análisis que se lleva a cabo con este modelo es puramente elástico.

Para el análisis de los efectos de ISE en este tipo de edificios, se diseñaron pruebas numéricas de dos modelos con distintas configuraciones estructurales. Se supone que los edificios son regulares y simétricos en planta, para poder ser representados por medio del modelo de viga de cortante. Se analizaron los modelos desplantados sobre roca y sobre arcillas representativas del valle de México con un periodo dominante de $2.5 \mathrm{~s}$.

Se evaluó la diferencia en la respuesta entre un edificio de configuración regular en elevación y este mismo edificio reduciendo la rigidez del primer entrepiso a un $20 \%$ de la del segundo nivel. Se calcularon las funciones de transferencia para la azotea y el primer nivel, así como el cortante basal máximo y la distorsión máxima del primer nivel. Se utilizó como movimiento de control el registro de CU del gran temblor de Michoacán de 1985, amplificado por los efectos del sitio de interés.

\section{MODELACIÓN MATEMÁTICA DEL PROBLEMA}

En el modelo investigado se consideraron tanto los efectos de sitio como los efectos de ISE. Para calcular los efectos de sitio se utilizó el modelo unidimensional de propagación de ondas mostrado en la figura 1. Esta aproximación es adecuada debido a la gran extensión del valle de México y al gran contraste entre las velocidades de ondas de corte de las arcillas superficiales y el basamento.

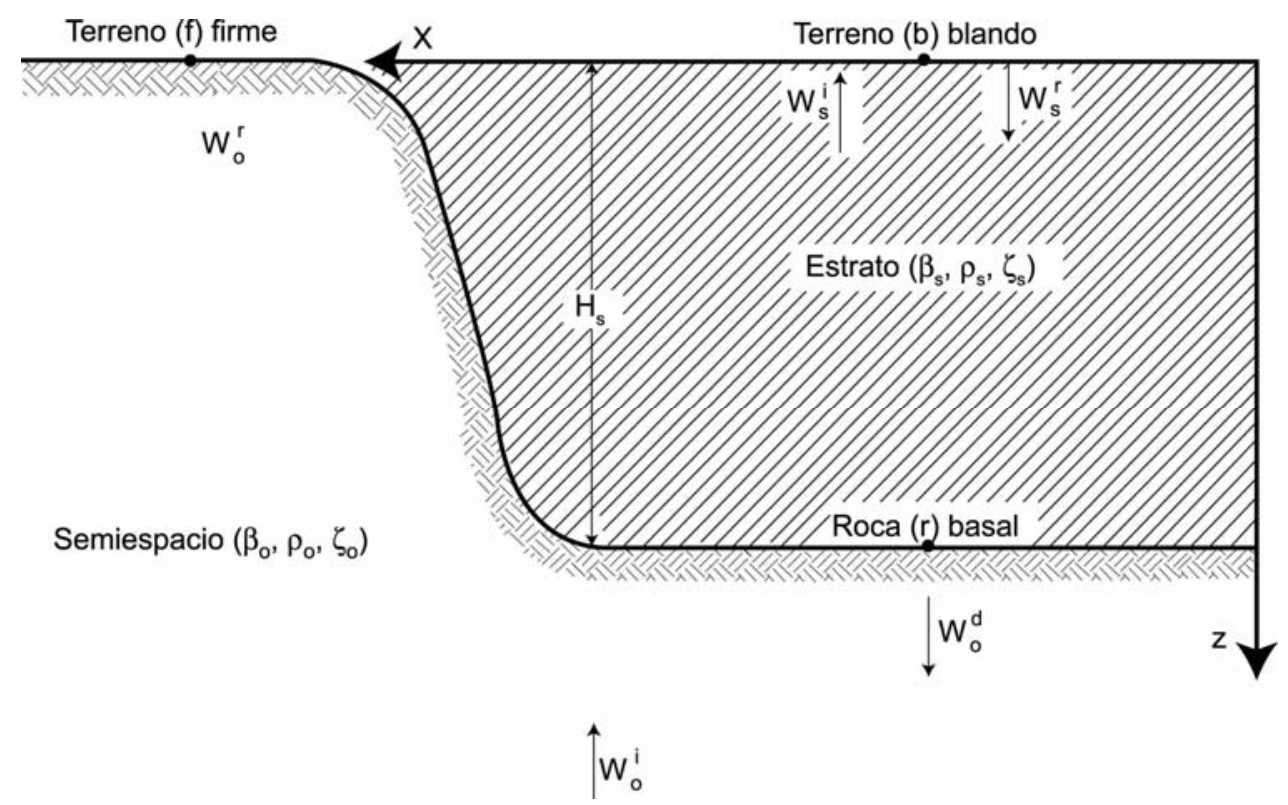

Figura 1. Modelo unidimensional de propagación de ondas para representar los efectos de sitio.

Se utilizó el concepto de función de transferencia para determinar las modificaciones a las que está sujeto el movimiento de terreno firme debido a la presencia de estratos blandos:

$$
w_{b}=H(\omega) w_{f}
$$


donde $w_{f}$ representa el movimiento de entrada en el punto $f, w_{b}$ el movimiento de salida en el punto $b$ y $H(\omega)$ la función de transferencia definida para un estrato homogéneo por Wolf (1985) de la manera siguiente:

$$
H(\omega)=\frac{\mathrm{e}^{i k_{0} H_{s}}}{\cos \left(k_{s} H_{s}\right)+i p \operatorname{sen}\left(k_{s} H_{s}\right)}
$$

donde $k_{s}=\omega / \beta_{s}$ y $k_{0}=\omega / \beta_{0}$ son los números de onda del estrato y el basamento, respectivamente, siendo $\omega$ la frecuencia de excitación y $\beta_{s, 0}$ las respectivas velocidades de onda de corte; $H_{s}$ es el espesor del estrato y $p=\frac{\rho_{s} \beta_{s}}{\rho_{0} \beta_{0}}$ la relación de impedancias entre el estrato y el basamento.

El amortiguamiento material de tipo histerético se introduce de manera aproximada afectando a las velocidades de propagación del estrato y el basamento por un factor $\sqrt{1+i 2 \zeta_{s, 0}}$, donde $\zeta_{s, 0}$ es el amortiguamiento del estrato (subíndice s) y el basamento (subíndice 0).

Como es sabido, los efectos de ISE pueden dividirse en dos partes (Whitman y Bielak, 1980). La primera se refiere a la respuesta de la estructura ante el movimiento que se presentaría en el terreno en ausencia de la misma, pero considerando la flexibilidad del apoyo. En este caso la diferencia entre la respuesta de la estructura con base flexible y la de base rígida proviene principalmente de la inercia y la flexibilidad del sistema completo. A este efecto se le conoce como interacción inercial y está controlado por la relación de rigideces entre la estructura y el suelo.

Para considerar la interacción inercial se sustituyen tanto la rigidez como el amortiguamiento del suelo por medio de los resortes y amortiguadores mostrados en la figura 2, cuyas propiedades dependen de la frecuencia.

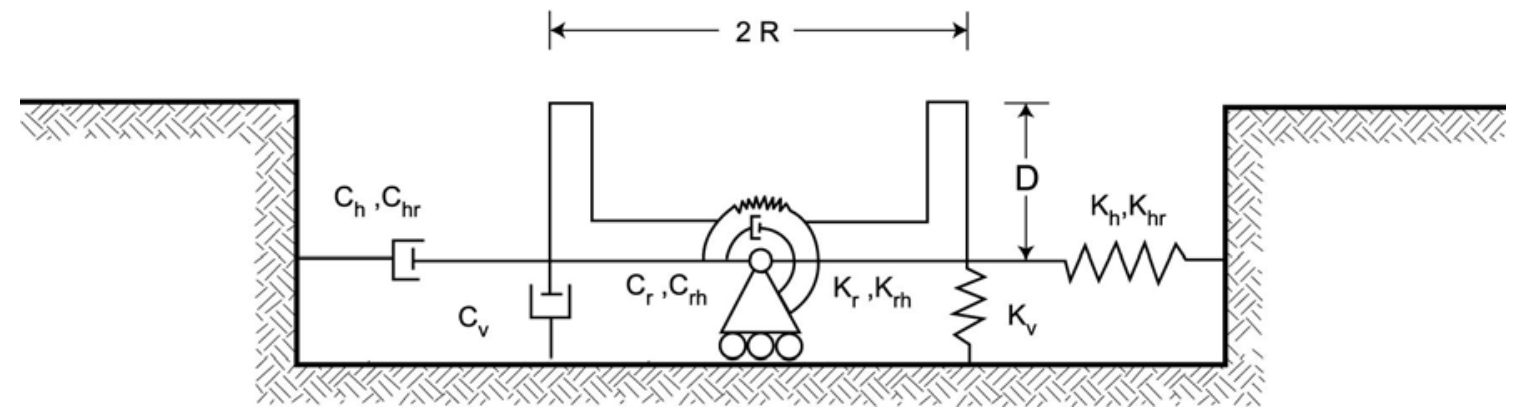

Figura 2. Resortes y amortiguadores equivalentes del suelo.

En este análisis no se considera el componente vertical del movimiento, por lo que los valores tanto del resorte $\mathrm{K}_{\mathrm{v}}$ como del amortiguador $\mathrm{C}_{\mathrm{v}}$ no son utilizados. 
Con base en la analogía con un oscilador, la rigidez dinámica de la cimentación para cualquier modo de vibración se acostumbra expresar mediante una función compleja dependiente de la frecuencia de excitación, de la forma (Gazetas, 1983)

$$
\widetilde{K}_{m}\left(\eta_{m}\right)=K_{m}^{o}\left[k_{m}\left(\eta_{m}\right)+i \eta_{m} c_{m}\left(\eta_{m}\right)\right]\left(1+i 2 \zeta_{s}\right)
$$

donde $m$ indica traslación horizontal $(m=h)$, cabeceo $(m=r)$ o acoplamiento $(m=h r)$. El factor complejo $\left(1+i 2 \zeta_{s}\right)$ intenta aislar el efecto del amortiguamiento material del suelo $\zeta_{s}$ en los coeficientes de rigidez y amortiguamiento. Por su parte, $K_{m}^{o}$ es la rigidez estática mientras que $k_{m}$ y $c_{m}$ son respectivamente los coeficientes de rigidez y amortiguamiento geométrico del suelo dependientes de la frecuencia normalizada $\eta_{m}$, definida como

$\eta_{m}=\frac{\omega R_{m}}{\beta_{s}}$

donde $R_{m}$ es el radio de un círculo equivalente a la superficie de desplante de la cimentación, con igual área o igual momento de inercia que dicha superficie, esto es:

$$
\begin{aligned}
& R_{h}=R_{h r}=\left(\frac{A}{\pi}\right)^{1 / 2} \\
& R_{r}=\left(\frac{4 I}{\pi}\right)^{1 / 4}
\end{aligned}
$$

donde $A$ es el área de la superficie neta de cimentación e $I$ el momento de inercia de dicha superficie con respecto a su eje centroidal de rotación, perpendicular a la dirección de análisis.

Los valores de las rigideces estáticas y de los coeficientes de rigidez y amortiguamiento del suelo dependientes de la frecuencia se calcularon de acuerdo a las fórmulas presentadas por Gazetas (1991) y Sieffert y Cevaer (1992).

La segunda parte de la ISE consiste en la modificación que presenta el movimiento al cuál se sujeta la estructura. Esta variación es debida principalmente a la gran rigidez de la cimentación en comparación con la del terreno, lo cual evita que los elementos que componen la cimentación se deformen de la misma manera que el terreno. Esto genera la difracción y refracción de ondas por la cimentación. Este efecto es conocido como interacción cinemática.

Para considerar la interacción cinemática, en este trabajo se optó por utilizar una solución aproximada desarrollada por Kausel et al (1978). Usando el método de elementos finitos, estos autores estudiaron la respuesta de una cimentación circular enterrada en un estrato elástico con base rígida, ante la incidencia vertical de ondas de cortante. Para obtener expresiones simplificadas, realizaron un análisis paramétrico donde variaron el enterramiento de la cimentación y el espesor del estrato en un amplio intervalo de interés práctico. Así dedujeron la función de transferencia para el movimiento de entrada en la base de la cimentación entre el movimiento de campo libre. 
Una vez conocidos el movimiento de entrada y las funciones de impedancia (resortes y amortiguadores equivalentes del suelo), la estructura es modelada como una viga de cortante con $N$ grados de libertad en traslación lateral. Si se consideran los grados de libertad que corresponden a la traslación y el cabeceo de la base se establece un sistema de $N+2$ grados de libertad, como se muestra en la figura 3 . Debido a que las funciones de impedancia dependen de la frecuencia de excitación y de que no existen modos clásicos de vibración, para determinar la respuesta del sistema es conveniente utilizar el método de la respuesta compleja en la frecuencia en conjunto con la síntesis de Fourier (Chopra, 1995).

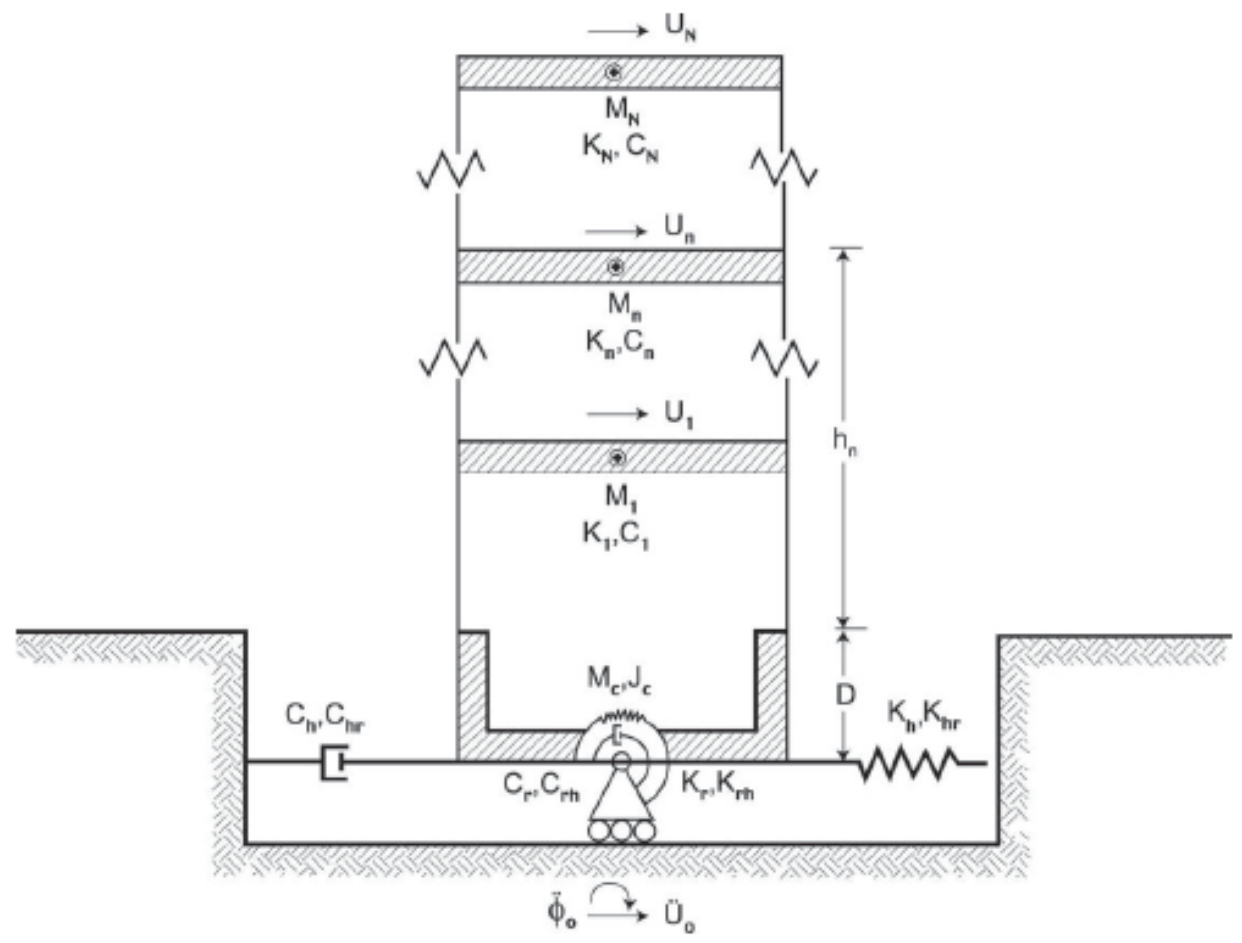

Figura 3. Sistema suelo-estructura completo.

Los grados de libertad del sistema suelo-estructura son: $\left\{U_{e}\right\}$, el vector de desplazamientos de la estructura relativos a su base; $U_{c}$, el desplazamiento de la base relativo al movimiento efectivo $U_{0}$ de traslación; y $\Phi_{c}$, la rotación de la base relativa al movimiento efectivo $\Phi_{0}$ de rotación. De acuerdo con lo anterior, el vector de desplazamientos de la estructura es: $\left(U_{0}+U_{c}\right)\{I\}+\left(\Phi_{0}+\Phi_{c}\right)\{H\}+\left\{U_{e}\right\}$, siendo $\{I\}=\{1,1, \ldots, 1\}^{T}$ y $\{H\}=\left\{\left(h_{1}+D\right),\left(h_{2}+D\right), \ldots,\left(h_{N}+D\right)\right\}^{T}$. Las ecuaciones de movimiento del sistema pueden obtenerse a partir del equilibrio dinámico de fuerzas en la estructura, así como de fuerzas y momentos en la cimentación, esto es:

$$
\begin{aligned}
& {\left[M_{e}\right]\left\{\dot{U}_{c}\{I\}+\ddot{\Phi}_{c}\{H\}+\left\{\dot{U}_{e}\right\}\right\}+\left[C_{e}\right]\left\{U_{e}\right\}+\left[K_{e}\right]\left\{U_{e}\right\}=-\left[M_{e}\right]\left\{\dot{U}_{0}\{I\}+\dot{\Phi}_{0}\{H\}\right\}} \\
& M_{c}\left(\dot{U}_{c}+E \ddot{\Phi}_{c}\right)+C_{h} \dot{U}_{c}+C_{h r} \Phi_{c}+K_{h} U_{c}+K_{h r} \Phi_{c}-V_{0}=-M_{c}\left(\dot{U}_{0}+E \Phi_{0}\right)
\end{aligned}
$$


$J_{c}^{\prime} \ddot{\Phi}_{c}+C_{r} \Phi_{c}+C_{h r} \dot{U}_{c}+K_{r} \Phi_{c}+K_{h r} U_{c}+M_{c} E\left(\ddot{U}_{c}+E \ddot{\Phi}_{c}\right)-M_{0}=$

$-J_{c}^{\prime} \Phi_{0}-M_{c} E\left(\dot{U}_{0}+E \Phi_{0}\right)$

donde $\left[M_{e}\right],\left[C_{e}\right]$ y $\left[K_{e}\right]$ son las matrices de masa, amortiguamiento y rigidez de la estructura con base rígida; $J_{c}^{\prime}=J_{c}-M_{c} E^{2}$ es el momento de inercia con respecto al centroide de la cimentación. Además, $V_{0}=\{I\}^{T}\left\{\left[C_{e}\right]\left\{U_{e}\right\}+\left[K_{e}\right]\left\{U_{e}\right\}\right\}$ es el cortante en la base de la estructura y $M_{0}=[H]^{T}\left\{\left[C_{e}\right]\left\{U_{e}\right\}+\left[K_{e}\right]\left\{U_{e}\right\}\right\}$ el momento de volteo en la base de la cimentación.

Las matrices de masa y rigidez de la estructura tienen la siguiente forma:

$$
\begin{aligned}
& {\left[M_{e}\right]=\left[\begin{array}{cccc}
M_{1} & 0 & \cdots & 0 \\
0 & M_{2} & \cdots & 0 \\
\vdots & \vdots & \ddots & \vdots \\
0 & 0 & \cdots & M_{N}
\end{array}\right]} \\
& {\left[K_{e}\right]=\left[\begin{array}{cccc}
k_{1}+k_{2} & -k_{2} & \cdots & 0 \\
-k_{2} & k_{2}+k_{3} & \cdots & 0 \\
\vdots & \vdots & \ddots & \vdots \\
0 & 0 & \cdots & k_{N}
\end{array}\right]}
\end{aligned}
$$

donde $M_{1}, M_{2}, \ldots, M_{N}$ son las masas concentradas y $k_{1}, k_{2}, \ldots, k_{N}$ las rigideces de entrepiso. A diferencia de la matriz de rigidez, la matriz de amortiguamiento de la estructura no puede construirse a partir de los amortiguamientos de entrepiso, ya que estas cantidades no están bien establecidas. Para construir la matriz de amortiguamiento se siguió la metodología descrita por Crouse y McGuire (2001).

Si el cortante y momento de volteo basales se expresan en términos de la ecuación 7 y sustituyen en las ecuaciones 8 y 9, respectivamente, se encuentra que las ecuaciones de movimiento del sistema tienen la siguiente forma matricial:

$$
\left[M_{s}\right]\left\{\dot{U}_{s}\right\}+\left[C_{s}\right]\left\{U_{s}\right\}+\left[K_{s}\right]\left\{U_{s}\right\}=-\dot{U}_{0}\left\{M_{0}\right\}-\check{\Phi}_{0}\left\{J_{0}\right\}
$$

donde $\left\{U_{s}\right\}=\left\{\left\{U_{s}\right\}^{T}, U_{c}, \Phi_{c}\right\}^{T}$ es el vector de desplazamientos del sistema, de orden $N+2$. Además, $\left\{M_{0}\right\}$ y $\left\{J_{0}\right\}$ son vectores de carga definidos como

$$
\left\{M_{0}\right\}=\left\{\begin{array}{c}
{\left[M_{e}\right]\{I\}} \\
\{I\}^{T}\left[M_{e}\right]\{I\}+M_{c} \\
\{H\}^{T}\left[M_{e}\right]\{I\}+M_{c} E
\end{array}\right\}
$$




$$
\left\{J_{0}\right\}=\left\{\begin{array}{c}
{\left[M_{e}\right]\{H\}} \\
\{I\}^{T}\left[M_{e}\right]\{H\}+M_{c} E \\
\{H\}^{T}\left[M_{e}\right]\{H\}+J_{c}
\end{array}\right\}
$$

mientras que $\left[M_{s}\right],\left[C_{s}\right]$ y $\left[K_{s}\right]$ son las matrices de masa, amortiguamiento y rigidez del sistema, estructuradas de las siguientes formas:

$$
\begin{aligned}
& {\left[M_{s}\right]=\left[\begin{array}{ccc}
{\left[M_{e}\right]} & {\left[M_{e}\right]\{I\}} & {\left[M_{e}\right]\{I\}} \\
\{I\}^{T}\left[M_{e}\right] & \{I\}^{T}\left[M_{e}\right]\{I\}+M_{c} & \{I\}^{T}\left[M_{e}\right]\{H\}+M_{c} E \\
\{H\}^{T}\left[M_{e}\right] & \{I\}^{T}\left[M_{e}\right]\{I\}+M_{c} E & \{H\}^{T}\left[M_{e}\right]\{H\}+J_{c}
\end{array}\right]} \\
& {\left[C_{s}\right]=\left[\begin{array}{lll}
{\left[C_{e}\right]} & \{0\} & \{0\} \\
\{0\}^{T} & C_{h} & C_{h r} \\
\{0\}^{T} & C_{h r} & C_{r}
\end{array}\right]} \\
& {\left[K_{s}\right]=\left[\begin{array}{lll}
{\left[K_{e}\right]} & \{0\} & \{0\} \\
\{0\}^{T} & K_{h} & K_{h r} \\
\{0\}^{T} & K_{h r} & K_{r}
\end{array}\right]}
\end{aligned}
$$

Los términos $C_{m}$ y $K_{m}$, con $m=h, r, h r$, representan los resortes y amortiguadores equivalentes del suelo. Aplicando trasformada de Fourier en ambos miembros de la ecuación 12 , la ecuación matricial de movimiento del sistema se reduce a

$$
\left[\left[K_{s}\right]+i \omega\left[C_{s}\right]-\omega^{2}\left[M_{s}\right]\right]\left\{U_{s}(\omega)\right\}^{*}=\omega^{2} U_{g}^{*}(\omega)\left\{Q_{h}(\omega)\left\{M_{0}\right\}+Q_{r}(\omega)\left\{J_{0}\right\}\right\}
$$

donde $\left\{U_{s}(\omega)\right\}^{*}$ y $U_{g}^{*}(\omega)$ representan respectivamente las trasformadas de Fourier de la respuesta $\left\{U_{s}(t)\right\}$ y la excitación $U_{g}(t)$ del sistema. Al multiplicar el término de la izquierda por $\omega^{2}$ se considera que la respuesta $\left\{U_{s}(\omega)\right\}^{*}$ esta dada en aceleración.

Resolviendo la ecuación 18 se obtiene la respuesta en la frecuencia del sistema. Los renglones del vector $\left\{U_{s}(\omega)\right\}^{*}$ corresponden a la aceleración para cada uno de los grados de libertad del sistema. Para encontrar la respuesta en términos de desplazamiento, se utiliza la siguiente expresión que es la relación general que existe entre desplazamiento y aceleración para la respuesta en frecuencia

$S a(\omega)=\omega^{2} S d(\omega)$

donde $S a(\omega)$ es la aceleración y $S d(\omega)$ el desplazamiento. 
Una vez establecidas las respuestas tanto de aceleración como de desplazamiento en la frecuencia, es posible determinar la correspondiente respuesta en el tiempo utilizando la antitrasformada de Fourier. Para ello suele recurrirse al algoritmo de la transformada rápida de Fourier (Paz, 1980).

\section{PRUEBAS NUMÉRICAS}

En este trabajo se busca identificar la influencia de la flexibilidad del terreno en la respuesta dinámica de estructuras con primer piso blando. Se analizó un modelo que representa un edificio de características comunes y estructuración regular en altura al que se llamará modelo original (M10reg). El modelo con piso flexible (M10pf) está basado en el modelo original pero con una rigidez del primer entrepiso de sólo el $20 \%$ de la rigidez del segundo nivel. Este contraste de rigidez tan alto es difícil de encontrar en un caso real, pero se ha decidido hacer de esta manera para que los fenómenos relacionados con la presencia de piso flexible sean más evidentes. En cuanto al terreno de desplante, se utilizaron propiedades representativas del subsuelo del valle de México, con un periodo dominante del sitio que es común en la zona blanda de la ciudad.

Los análisis se llevaron a cabo en el dominio de la frecuencia. Los resultados se presentan en términos de funciones de transferencia entre la azotea y el movimiento de entrada, así como funciones de transferencia entre el primer nivel y el movimiento de campo libre. También se realizó un análisis paramétrico para conocer los valores de los cortantes basales máximos y las distorsiones máximas del primer entrepiso de los modelos desplantados sobre distintas condiciones de terreno.

Se analizó la respuesta de un edificio con 10 niveles. Para ello se utilizaron los dos modelos antes mencionados, uno con regularidad estructural en altura (M10reg) y uno con primer piso flexible (M10pf). Las frecuencias naturales y algunas de las propiedades de cada uno de los modelos se reportan en las tablas 1 y 2, respectivamente.

Tabla 1. Periodos y frecuencias fundamentales de los modelos considerados.

\begin{tabular}{ccc}
\hline Nombre & $T_{e}$ & $\omega_{e}$ \\
\hline M10reg & 1.16 & 5.4 \\
M10pf & 1.57 & 4 \\
\hline
\end{tabular}

Tabla 2. Propiedades generales de los modelos considerados.

\begin{tabular}{cccccc}
\hline Nombre & $M_{e}$ & $M_{c}$ & $R$ & $H_{e}$ & $D$ \\
\hline M10reg & 330.28 & 79.53 & 11.28 & 30.5 & 5.00 \\
M10pf & 330.28 & 79.53 & 11.28 & 30.5 & 5.00 \\
\hline
\end{tabular}

El modelo estudiado en este trabajo considera un sólo estrato homogéneo con una velocidad de propagación de ondas de cortante de $\beta_{\mathrm{s}}=75 \mathrm{~m} / \mathrm{s}$, como un valor representativo de las velocidades que se presentan en los suelos del valle de México que oscilan entre los 50 y los 100 m/s.

Para identificar los efectos principales de la combinación de efectos de ISE y el primer piso blando se diseñaron dos grupos de pruebas. En el primero se analizó la respuesta de los modelos desplantados sobre distintas condiciones de terreno. Para tener un resultado de referencia, se diseñaron pruebas 
considerando los edificios desplantados en terreno firme, sin efectos de ISE ni de sitio, con la velocidad de las ondas de cortante en el estrato igual a la de la roca basal $\left(\beta_{\mathrm{s}}=1000 \mathrm{~m} / \mathrm{s}\right)$.

Posteriormente se realizaron pruebas de los modelos desplantados sobre un estrato blando de espesor $H_{\mathrm{s}} \sim 50 \mathrm{~m}$ y velocidad de ondas de corte $\beta_{\mathrm{s}}=75.0 \mathrm{~m} / \mathrm{s}$, lo que llevó a tener un terreno con periodo dominante $T_{s}=2.5 \mathrm{~s}$. Se buscó analizar una condición de suelo blando representativa de una gran parte del valle, donde se presentan las mayores amplificaciones del movimiento del terreno por efectos de sitio.

En este grupo de pruebas los resultados se encontraron en términos de las funciones de transferencia. Se obtuvieron funciones de transferencia entre el movimiento relativo con respecto a la base, tanto de la azotea como del primer piso, y el componente traslacional del movimiento del campo libre. Las funciones de transferencia están expresadas en función de la frecuencia.

Con estos resultados se busca observar la influencia que tienen los efectos estudiados tanto en las amplificaciones del movimiento como en los parámetros dinámicos principales de la estructura, tales como frecuencias naturales y amortiguamiento, eliminando la influencia de los efectos de sitio. En la tabla 3 se presentan los parámetros adimensionales que caracterizan al sitio.

Tabla 3. Parámetros característicos del sitio para las pruebas diseñadas. Terreno Firme

\begin{tabular}{ccccccc}
\hline Nombre & $R / \beta_{s}$ & $\beta_{s}$ & $T_{s}$ & $H_{s}$ & $H_{s} / R$ & $\gamma$ \\
\hline M10reg & 0.0113 & 1000 & 1.00 & 250.00 & 22.16 & 95.373 \\
M10pf & 0.0113 & 1000 & 1.00 & 250.00 & 22.16 & 128.754 \\
\hline
\end{tabular}

\begin{tabular}{ccccccc}
$\mathrm{T}_{\mathrm{s}}=2.5 \mathrm{~s}$ & \multicolumn{1}{l}{${ }^{2}$} & & & & & \\
\hline Nombre & $R / \beta_{\mathrm{s}}$ & $\beta_{\mathrm{s}}$ & $T_{s}$ & $H_{s}$ & $H_{s} / R$ & $\gamma$ \\
\hline M10reg & 0.1504 & 75 & 2.50 & 46.88 & 4.16 & 0.7153 \\
M10pf & 0.1504 & 75 & 2.50 & 46.88 & 4.16 & 0.9657 \\
\hline
\end{tabular}

El segundo grupo consistió en encontrar las respuestas máximas (cortante basal y distorsión del primer entrepiso) de las estructuras consideras ante un sismo específico, modificando el periodo del sitio en que se desplantan desde 1 hasta $5 \mathrm{~s}$. En este caso se estudió un terreno con una rigidez sumamente baja para hacer más claros los efectos de interacción $\left(\beta_{\mathrm{s}}=50 \mathrm{~m} / \mathrm{s}\right)$.

Como resultados se presentan gráficas de la variación de las respuestas máximas en función del periodo dominante del sitio. Por otro lado, también se calcularon los cocientes entre las respuestas máximas de las estructuras con y sin efectos de ISE, así como los cocientes entre las respuestas máximas de las estructuras con y sin primer piso flexible, para poder apreciar en qué condiciones aumentan o disminuyen las respuestas.

\section{Funciones de transferencia}

Aquí se presentan resultados representativos del primer grupo de pruebas, poniendo énfasis en aquellos que permiten observar los fenómenos que se estudian en este trabajo. En la figura 4 se exhiben las funciones de transferencia entre la azotea y el movimiento de campo libre para los modelos M10reg y M10pf sobre base rígida, y para los mismos modelos sobre base flexible en un terreno blando con periodo igual a 2.5 s. En esta gráfica se pueden destacar algunos efectos interesantes. En primer lugar, se manifiesta la influencia tanto del primer piso flexible como de la ISE sobre la frecuencia fundamental del 
sistema. En ambos casos la frecuencia se modifica respecto a la del modelo M10reg sobre base rígida debido al aumento en la flexibilidad del modelo. Esta modificación es de aproximadamente $26 \%$ por la presencia del piso flexible, $24 \%$ por el efecto de la ISE y el 37\% para la combinación de los dos efectos. Estos resultados se pueden observar en la tabla 4.

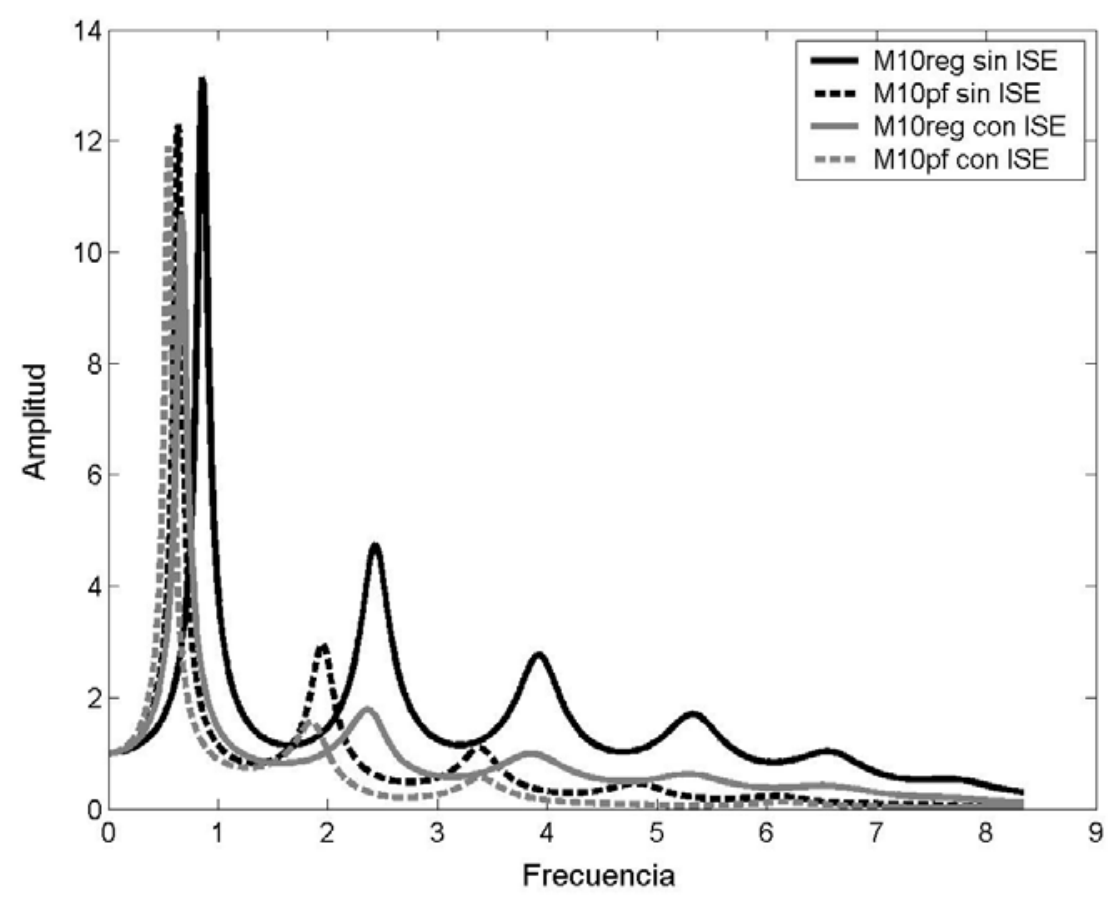

Figura 4. Funciones de transferencia de azotea de los modelos m10reg y m10pf con y sin efectos de ISE.

Tabla 4. Variación en las frecuencias fundamentales.

\begin{tabular}{cccc}
\hline Condición original & Condición modificada & $\mathrm{T}_{\mathrm{e}}$ modificado & $\begin{array}{c}\text { \% de variación de } \\
\text { frecuencia }\end{array}$ \\
\hline M10reg base rígida & M10pf base rígida & 1.57 & 26.1 \\
M10reg base rígida & M10reg base flexible & 1.53 & 23.7 \\
M10reg base rígida & M10pf base flexible & 1.85 & 37.3 \\
\hline
\end{tabular}

Otro aspecto a destacar es la reducción en la amplificación del movimiento con respecto al modelo M10reg sobre base rígida. En el caso de base flexible este fenómeno era de esperarse debido al amortiguamiento adicional por radiación. Por otra parte, se puede apreciar que, al considerar la base flexible y la presencia de un primer piso blando, el primer modo resulta ser relativamente más importante que los modos superiores.

Se corrobora que los efectos de ISE modifican de manera importante únicamente el valor de la frecuencia del primer modo, manteniendo las frecuencias de modos superiores casi invariables, mientras que la presencia del piso flexible modifica todas las frecuencias asociadas a los modos de respuesta, 
aunque sea ligeramente. Por otro lado, se aprecian las reducciones en las amplificaciones del movimiento en modos superiores, debidas a la interacción cinemática.

La amplificación del movimiento en la azotea del edificio es menor cuando se presenta una discontinuidad de rigidez en el sistema. Observando por separado los efectos de ISE y la influencia del primer piso flexible, se nota claramente como los valores del cociente espectral entre el movimiento en la azotea y el movimiento de campo libre son menores que para el caso de regularidad en altura. Esta reducción se debe al amortiguamiento extra que introduce la base flexible, amortiguamiento causado por la radiación de ondas. Se produce gracias a la capacidad de la cimentación de liberar energía en forma de ondas que viajan al interior del estrato de desplante, y crece a medida que el estrato de suelo tiene un espesor mayor hasta un valor límite a partir del cual se puede considerar al estrato como un semiespacio infinito. La presencia del primer piso flexible no influye en este fenómeno.

Tanto los efectos de ISE como del primer piso flexible se traducen en una mayor participación del modo fundamental del sistema, pero en magnitudes distintas. La influencia de los efectos de ISE en este fenómeno se puede atribuir al movimiento de cuerpo rígido de la estructura. El modo fundamental de un sistema de varios grados de libertad corresponde a una configuración dinámica en la cual todas las masas del sistema se están desplazando hacia la misma dirección. Cuando una estructura desplantada sobre terreno blando es sometida a una carga dinámica, presenta efectos de cabeceo y traslación de cuerpo rígido. Esta flexibilidad de la base, genera que los modos superiores tengan una menor participación.

Al considerar cada uno de los fenómenos (ISE y primer piso flexible) por separado en el análisis de las amplitudes de los primeros modos en la función de transferencia, se muestra que no siempre existirá una reducción a medida que el sistema sea más flexible, como sucede para la frecuencia fundamental, aunque al introducir ambos fenómenos la amplificación del movimiento es más pequeña que la de las condiciones regulares sobre base rígida al menos para los modelos aquí analizados.

En la figura 5 se presentan las funciones de transferencia entre la traslación del primer nivel y el movimiento en campo libre. Algunos fenómenos distintos se observan cuando se refiere a la amplificación del primer nivel. Debido a que las frecuencias naturales del sistema deben ser las mismas independientemente del nivel que se esté analizando, las variaciones en la frecuencia son iguales. Con respecto a las amplificaciones de la respuesta estructural, los efectos difieren. Como era de esperarse, las amplificaciones del modelo M10pf son considerablemente mayores que las del modelo M10reg, debido al contraste de rigideces entre el primer y segundo entrepisos.

Un fenómeno no anticipado es el aumento en la amplificación de la respuesta cuando se introduce la flexibilidad del suelo en el modelo con regularidad en altura. Aquí se observa claramente como, cuando se trata de una estructura regular, la consideración de los efectos de ISE aumenta la amplificación de la respuesta, mientras que si se tiene un contraste de rigideces importante en los primeros niveles, el efecto de ISE disminuye la amplitud de la función de transferencia.

La presencia del piso flexible puede aumentar de manera considerable la amplificación del movimiento en el primer nivel, pero los efectos de ISE también pueden contribuir al aumento de la amplificación del movimiento en este entrepiso, ya que la introducción del cabeceo de la estructura produce que el primer modo se lleve una participación mayor que los modos superiores. Nuevamente, y de una manera mucho más clara, se puede percibir como los efectos de ISE y la presencia del primer piso flexible, propician una mayor contribución del primer modo en la respuesta global de la estructura. 


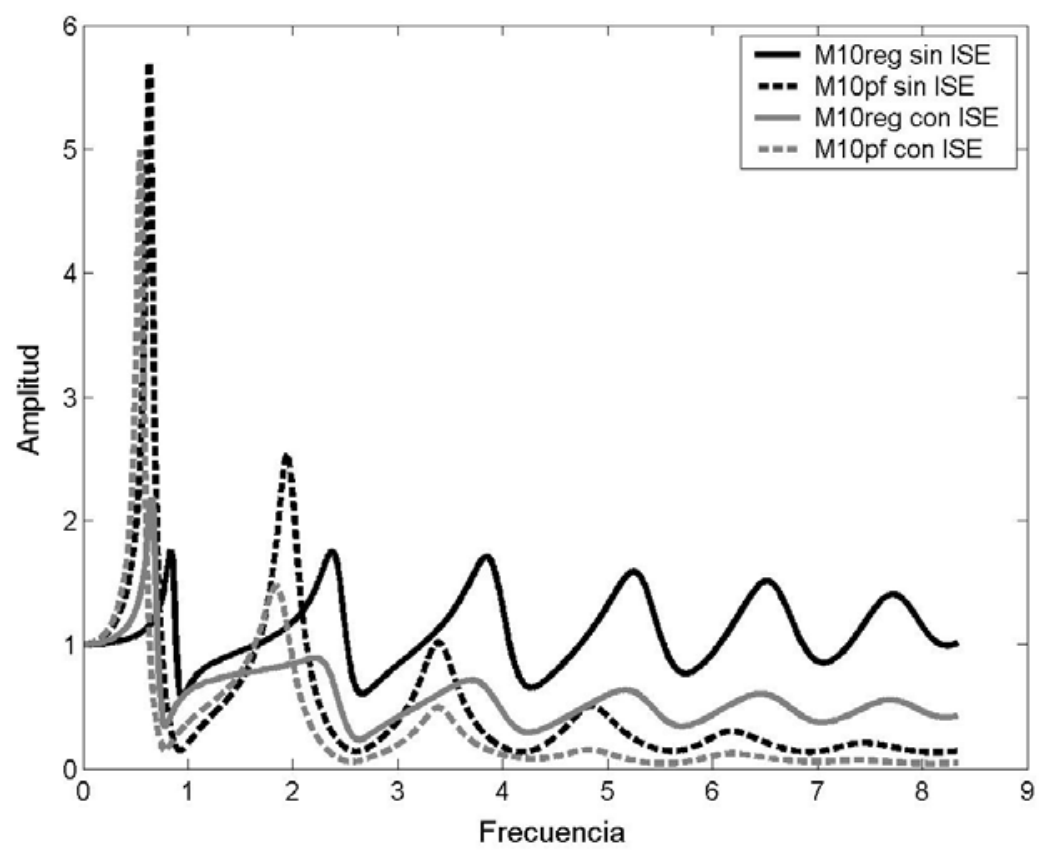

Figura 5. Funciones de transferencia del primer nivel de los modelos m10reg y m10pf con y sin efectos de ISE.

Con los resultados de la tabla 4 se puede apreciar que a medida que el parámetro de interacción $\gamma=T_{e} H_{s} / T_{s} H_{e}$ reportado en la tabla 3 tiene valores más pequeños, la influencia de los efectos de ISE es mayor. Como puede observarse, para el modelo con piso blando (M10pf) los valores de este parámetro son mayores que para el modelo regular (M10reg), por lo cual no es sorpresivo que la diferencia de las amplitudes en la funciones de transferencia de los casos con y sin ISE en el modelo M10pf sea más pequeña que la diferencia que existe entre las amplitudes de las funciones de transferencia del modelo (M10reg) con y sin ISE.

Como ya se mencionó, en los resultados presentados hasta el momento sólo se ha analizado la influencia de los efectos de ISE y el primer piso flexible en las propiedades dinámicas de los sistemas. Este es un análisis valioso, ya que permite ver cómo se afectan estas propiedades, pero no es suficiente para determinar en casos específicos si los efectos son benéficos o dañinos. Es por esta razón que se diseño otro grupo de pruebas, en las cuales se determina la influencia de los efectos aquí descritos en parámetros que inciden directamente en el comportamiento de la estructura, como son el cortante basal máximo y la distorsión máxima del primer entrepiso.

\section{Cortante basal y distorsión de entrepiso}

Para estas pruebas se utilizó como movimiento de control el sismo del 19 de septiembre de 1985 registrado en CU, cuyo espectro de amplitudes de Fourier se muestra en la figura 6. Esta excitación tiene un intervalo dominante de periodos entre 1 y 3.3 s, con una amplificación especialmente importante alrededor de $2 \mathrm{~s}$. 
En la figura 7 se presenta la variación del cortante basal máximo en función del periodo dominante del sitio. Se utilizaron los modelos M10reg y M10pf, cada uno considerando base rígida y base flexible. En todos los casos se consideraron los efectos de sitio suponiendo un suelo con velocidad de propagación de ondas de cortante de $\beta_{\mathrm{s}}=50 \mathrm{~m} / \mathrm{s}$. Puede observarse que el cortante basal resonante se presenta para periodos de sitio cercanos a los periodos de cada uno de los sistemas (ver tablas 1 y 4). Claramente se observa que el periodo del sistema se alarga más por ISE que por piso flexible.

En este caso, el sistema que presenta el mayor cortante basal máximo es el que corresponde al modelo M10pf sobre base flexible debido a un fenómeno de doble-resonancia. En primera instancia, el suelo con periodo cercano a los $2 \mathrm{~s}$ entra en resonancia con el movimiento de control cuyo periodo característico es del mismo orden, y a su vez el modelo M10pf sobre base flexible entra en resonancia con el movimiento de entrada.

Para los otros tres sistemas presentados en esta figura (modelo M10reg con y sin ISE y modelo M10pf sobre base rígida), se presenta un aumento en el valor del cortante basal a medida que la rigidez del sistema es mayor. Con excepción del sistema cuyo periodo dominante se encuentra alrededor de los $2 \mathrm{~s}$, es clara la tendencia del cortante basal máximo a crecer a medida que el sistema tiene una mayor rigidez. Para el caso en que la rigidez del primer entrepiso es muy baja (piso blando) es lógico considerar que el cortante basal sea menor, ya que a menor rigidez el sistema toma menos fuerza. La disminución en la magnitud del cortante basal cuando se introducen los efectos de ISE se puede achacar al mayor nivel de amortiguamiento que tiene el sistema. (Esta parte está mal redactada o la interpretación es incorrecta, pero definitivamente no la entiendo).

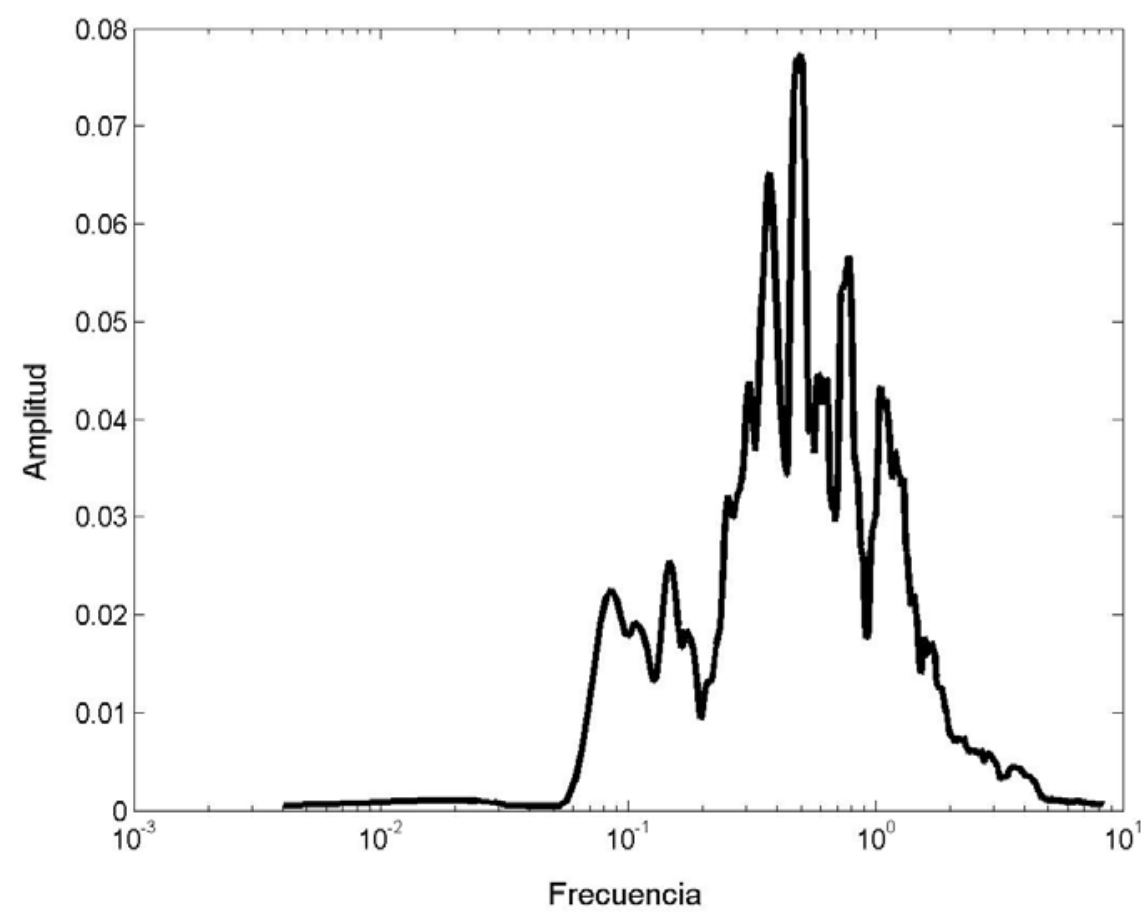

Figura 6. Espectro de amplitudes fourier del sismo de control. 


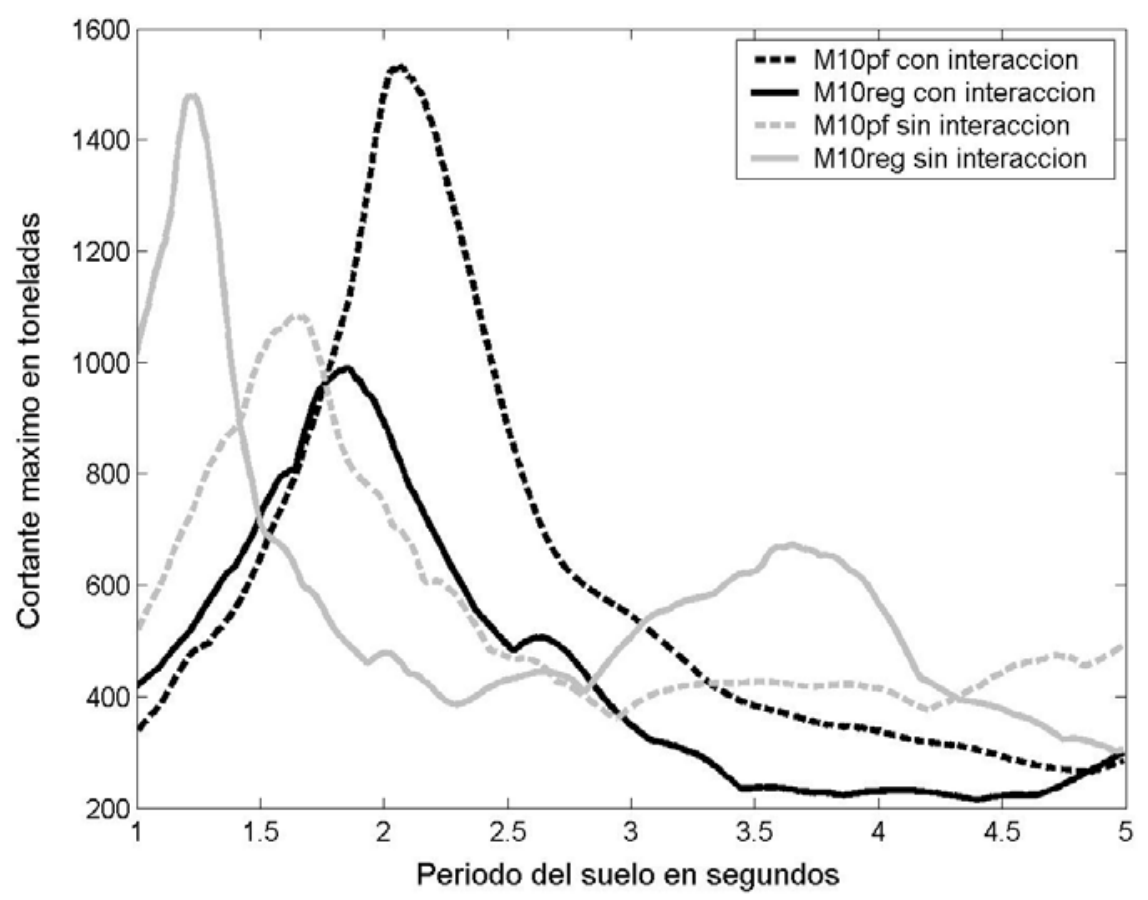

Figura 7. Variación del cortante basal máximo.

Se calcularon los cocientes entre los cortantes basales máximos de los modelos M10pf y M10reg en función del periodo dominante del sitio, para las condiciones de base rígida y flexible. Estos resultados se muestran en la figura 8. Cuando se realiza el análisis sin considerar los efectos de ISE pueden definirse claramente tres zonas. La primera entre 1 y $1.5 \mathrm{~s}$ en donde la presencia del piso flexible reduce el valor del cortante basal. Obviamente esta reducción obedece a la modificación del periodo de la estructura, ya que el modelo M10reg con base rígida presenta un periodo natural de $1.16 \mathrm{~s}$. En la segunda zona ubicada entre 1.5 y 2.5 s sucede un efecto contrario al presentarse la resonancia del sistema M10pf, por lo que la relación de cortantes basales resulta ser mayor que la unidad. En la tercera zona comprendida entre 2.5 y 4 $\mathrm{s}$, nuevamente el valor del cociente es menor que uno. A partir de los $4 \mathrm{~s}$, otra vez el cociente toma valores por arriba de la unidad, lo que sugiere que la gráfica presentará una forma relativamente periódica, demostrando que el beneficio o detrimento del piso flexible, depende de las zonas de resonancia de la estructura.

$\mathrm{Al}$ momento de introducir los efectos de ISE los resultados cambian considerablemente. Solamente se delimitan dos zonas, una comprendida entre 1 y $1.8 \mathrm{~s}$ en donde el cortante basal del modelo M10reg es mayor que el del modelo M10pf. A partir de $1.8 \mathrm{~s}$ y hasta casi $5 \mathrm{~s}$ ocurre lo contrario. En el análisis no hay que perder de vista que el periodo dominante del movimiento de control es $2 \mathrm{~s}$, lo que produce amplificaciones muy importantes en los sitios con periodo natural cercano a este valor.

Para medir la importancia de los efectos de ISE, se compararon las respuestas de cada uno de los modelos (M10reg y M10pf) sobre base flexible con respecto a las respuestas de estos mismos modelos considerando base rígida. Los resultados se muestran en la figura 9. La forma de los cocientes en función del periodo del sitio es similar para ambos modelos. Salvo en las zonas de resonancia, los respectivos cortantes basales son menores cuando se considera la ISE. 


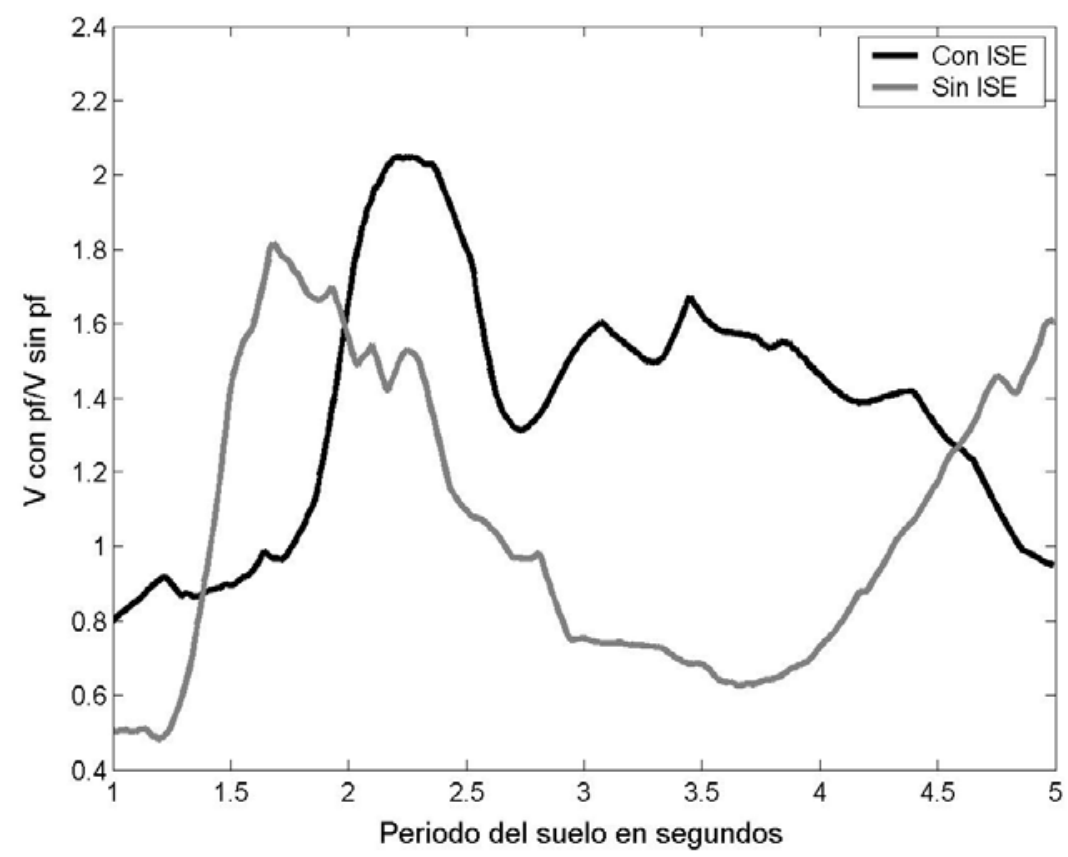

Figura 8. Cociente entre los cortantes basales máximos de los modelos m10pf y m10reg, con y sin efectos de ISE.

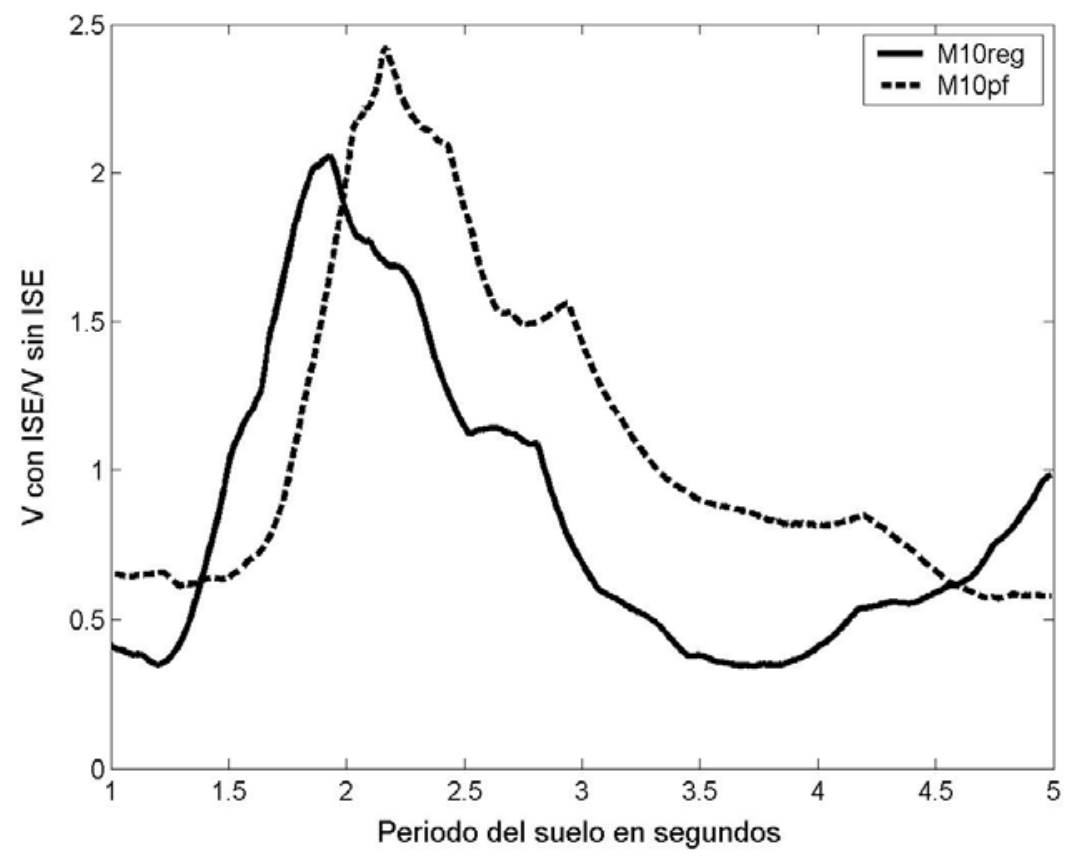

Figura 9. Cociente entre los cortantes basales máximos con y sin efectos de ise, para los modelos m10reg y m10pf. 
Como es bien sabido, las fuerzas a las que estarán sujetas las estructuras no son el único parámetro que interesa para evaluar su comportamiento sísmico. Una medida importante para el desempeño estructural es la distorsión máxima de entrepiso. En este caso se ha decidido estudiar el comportamiento del primer entrepiso. En la figura 10 se presenta la variación del cociente entre las distorsiones máximas calculadas para los modelos M10pf y M10reg, para las dos condiciones de apoyo (rígido y flexible). Aunque los valores del modelo M10pf siempre son mayores que los del modelo M10reg, se observa que la forma de los cocientes de distorsiones máximas es idéntica a la forma de los cocientes de cortantes basales máximos, lo que manifiesta la posibilidad de que la presencia de una discontinuidad importante en rigidez dentro del sistema afecte de igual manera, aunque a distinta escala, tanto las fuerzas a las que estará sujeta la estructura como las distorsiones que sufrirá. Este factor de escala está dado por la relación de las rigideces del primer entrepiso de los modelos M10reg y M10pf. Para este caso el factor es igual a 7.4.

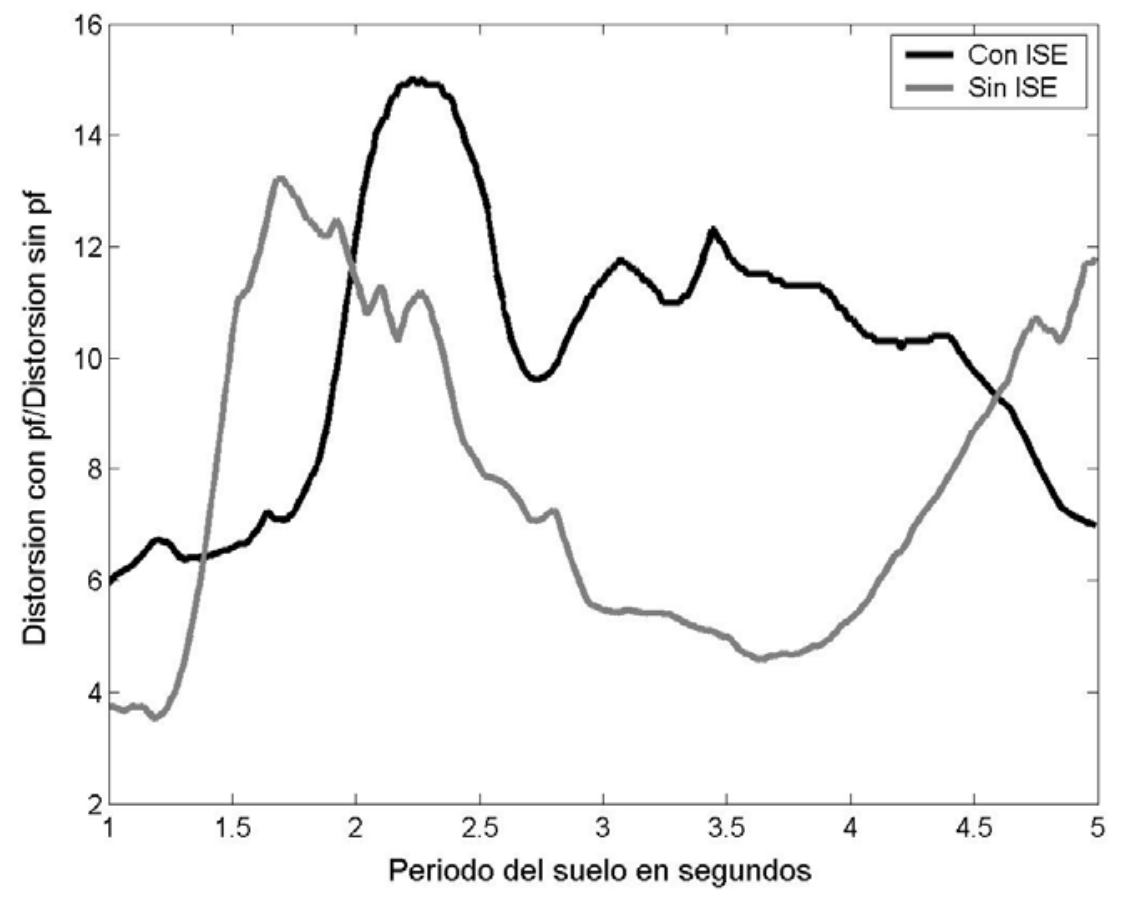

Figura 10. Cociente entre las distorsiones máximas del primer entrepiso de los modelos m10pf y m10reg, con y sin efectos de ISE.

Es interesante ver como una reducción con un factor de 5 en la rigidez del primer entrepiso con respecto a la estructura regular produce un aumento en un factor de hasta 15 en la distorsión del primer entrepiso y de más de 10 para un rango amplio de periodos de sitio, cuando se consideran los efectos de ISE. Obviamente, parte de esta distorsión corresponde al cabeceo de la estructura como cuerpo rígido la cual no demandará capacidad de deformación del entrepiso, pero influirá de manera importante en la generación de momentos de segundo orden $(\mathrm{P}-\Delta)$.

Posteriormente se procedió a hacer el análisis del cociente entre las distorsiones máximas del primer entrepiso calculadas para las condiciones de base flexible y rígida. La variación de dicho cociente se muestra en la figura 11, tanto para la estructura regular como para la irregular en altura. Nuevamente los valores de estos cocientes de distorsiones máximas son exactamente los mismos que los de la figura 9 para 
cortantes máximos. Por tratarse de análisis lineales, los efectos de ISE afectan por igual a los cortantes que a las distorsiones.

Analizando el valor de las distorsiones máximas de entrepiso se puede concluir lo siguiente. Según la física del problema, los sistemas con menor rigidez deberán presentar distorsiones mayores. Este hecho se observa claramente en la inclusión del primer piso flexible, ya que las distorsiones del primer entrepiso para estos modelos son mucho mayores que las distorsiones para los modelos con regularidad en altura debido a su menor rigidez. Además, como ya se mencionó anteriormente, el simple hecho de contar con un contraste de rigidez tan alto entre un nivel y otro, genera amplificaciones del movimiento a nivel local importantes.

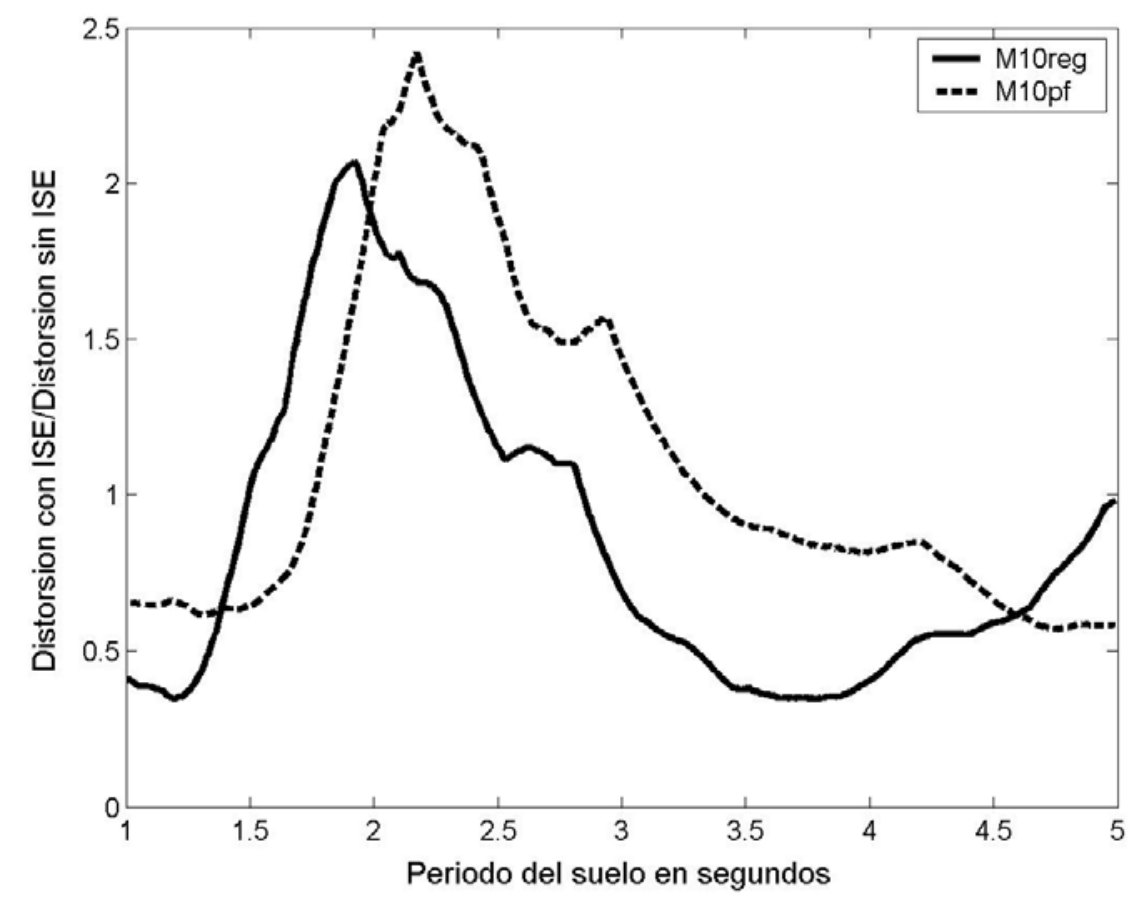

Figura 11. Cociente entre las distorsiones máximas del primer entrepiso con y sin efectos de ise, para los modelos m10reg y m10pf.

En el caso de la flexibilización del sistema debida a la consideración de los efectos de ISE, no siempre se presentan distorsiones mayores en comparación a los sistemas sobre base rígida. Este fenómeno puede tener dos explicaciones, la primera es que la reducción en las distorsiones se deba a la inclusión del amortiguamiento por radiación discutido previamente, y la segunda que la distorsión máxima de entrepiso se reduzca debido a que la estructura tiene un movimiento de cuerpo rígido importante, de suerte que aunque existan desplazamientos considerables en todos los niveles, la distorsión de entrepiso sea pequeña.

De aquí se puede inferir que, aunque los efectos de ISE y del primer piso flexible tengan repercusiones similares a nivel de función de transferencia, en términos de las respuestas máximas los efectos son distintos. Los cocientes entre las respuestas máximas de uno u otro sistema permiten 
identificar para qué casos los efectos son benéficos o perjudiciales. Estos cocientes presentan valores mayores que uno en las zonas donde los sistemas entran en resonancia. Esta observación demuestra que los efectos de ISE serán favorables o desfavorables dependiendo de la zona espectral en que se encuentre. En el caso del primer piso flexible, obviamente siempre se tendrá un efecto negativo en términos de la distorsión máxima del primer entrepiso, aún cuando el cambio de rigidez debida a este fenómeno aleje a la estructura de la zona de resonancia.

\section{CONCLUSIONES}

Los efectos de ISE y del primer piso blando se traducen en una mayor flexibilidad del sistema. En términos de las funciones de transferencia, ambos efectos son muy parecidos, pero las respuestas dinámicas máximas (cortantes y distorsiones) dependen de la zona espectral de interés.

La amplificación dinámica y las distorsiones en el primer entrepiso siempre se ven afectadas por el contraste de rigideces entre este nivel y el nivel superior. La influencia de la ISE hace menos crítico este problema. Ambos efectos producen una mayor participación del modo fundamental en relación con modos superiores. La influencia de la ISE se refleja casi exclusivamente en el primer modo, mientras que el primer piso blando modifica también las frecuencias de modos superiores.

Es claro que la presencia de un entrepiso blando siempre generará distorsiones de este entrepiso muy altas, pero no deja de llamar la atención que el factor por el cual se magnifican éstas con respecto a una estructura regular no es directamente proporcional al factor de reducción de rigidez, sino que puede duplicarlo o triplicarlo en algunos casos.

Cabe señalar que las conclusiones reportadas en este trabajo están basadas en resultados en el rango de comportamiento elástico. Se sabe, sin embargo, que cuando se considera el comportamiento inelástico los efectos de sitio tienden a ser contrarrestados por los efectos de ISE. Estos efectos aumentan el amortiguamiento y alargan el periodo al igual que la fluencia de la estructura.

\section{AGRADECIMIENTOS}

Agradecemos al CONACYT por el brindar los recursos para la elaboración de este artículo.

\section{REFERENCIAS}

Avilés J y Pérez-Rocha L E (1996), "Evaluation of Interaction Effects on the System Period and the System Damping due to Foundation Embedment and Layer Depth”, Soil Dynamics Earthquake Engineering, Vol 15, pp. 11-27.

Avilés J y Pérez-Rocha L E (1998), "Effects of foundation embedment during building-soil interaction”, Earthquake Engineering and Structural Dynamics, Vol. 27, pp. 1523-1540.

Chopra A (1995), Dynamics of Structures, Ed. Prentice Hall, Nueva Jersey.

Crouse C.B. y McGuire J (2001), “Energy Dissipation in Soil-Structure Interaction”, Earthquake Spectra, Vol 17, No. 2, pp 235-258. 
Gazetas G (1983), “Analysis of machine foundation vibrations: state of the art”, Soil Dynamics and Earthquake Engineering, Vol. 2, pp. 2-42.

Gazetas G (1991), Foundation vibrations, Foundation Engineering Handbook, Ed. H Y Fang, Van Nostrand Reinhold, Nueva York.

Gazetas G, Fan K, Kaynia A y Kausel E (1991), "Dynamic interaction factors for floating pile groups”, Journal of Geotechnical Engineering, ASCE, Vol. 117, pp. 1531-1548.

Jennings P C y Bielak J (1973), "Dynamics of building-soil interaction”, Bulletin of the Seismological Society of America, Vol. 63, pp. 9-48.

Kausel E, Whitman R V, Morray J P y Elsabee F (1978), “The spring method for embedded foundations”, Nuclear Engineering and Design, Vol. 48, pp. 377-392.

NTCDS-RCDF (2004), Normas técnicas complementarias para diseño por sismo, Reglamento de Construcciones para el Distrito Federal, Gaceta Oficial del Departamento del Distrito Federal.

Paz M (1980), Structural Dynamics: Theory and Computation, Van Nostrand Reinhold, Nueva York.

Sieffert J-G y Cevaer F (1992), Handbook of Impedance Functions, Ouest Editions, France.

Veletsos A S y Meek J W (1974), "Dynamic behaviour of building-foundation systems”, Earthquake Engineering and Structural Dynamics, Vol. 3, pp. 121-138.

Whitman R V y Bielak J (1980), Design Earthquake Resistant Structures: Foundations, Ed. E Rosenblueth, Pentech Press, Inglaterra.

Wolf J P (1985), Dynamic Soil-Structure Interaction, Prentice-Hall, Nueva Jersey. 